\title{
HISTORIA DE LAS IDEAS Y FILOSOFÍA POLÍTICA: NOTAS SOBRE UN ESTUDIO ACERCA DEL PENSAMIENTO CONSERVADOR EN CHILE
}

\author{
Carlos Peña \\ Universidad de Chile \\ Universidad Diego Portales \\ carlos.pena@udp.cl
}

\begin{abstract}
Resumen / Abstract
Este artículo analiza, a propósito de la obra de Renato Cristi y Carlos Ruiz (El pensamiento conservador en Chile, Editorial Universitaria, 2015) la relación entre historia de las ideas y filosofía política y examina bajo qué supuestos puede afirmarse que el pensamiento conservador tuvo un efecto constituyente de la cultura política del Chile contemporáneo.

Palabras clave: conservadurismo, Mannheim, historicismo, historia de las ideas, estilos de pensamiento, sociedad moderna.
\end{abstract}

\section{HISTORY OF IDEAS AND THE POLITICAL PHILOSOPHY: NOTES ON A STUDY OF CONSERVATIVE THOUGHT IN CHILE}

This article analyses, a propós the Chilean Conservative Thought by Cristi y Ruiz, the relationship between history of ideas and political philosophy. In addition, the text draws the attention about the presuppositions that underlie in the thesis according to which the conservative thought had an performative effect in the chilean political culture.

KEY WORDS: conservadurismo, Mannheim, historicismo, historia de las ideas, estilos de pensamiento, sociedad moderna.

$\overline{R A}$ La reedición del libro El pensamiento conservador en Chile, de los profesores Carlos Ruiz y Renato Cristi (Santiago: Editorial Universitaria, 2015) permite volver sobre un problema que aqueja a la filosofía cada vez que ella se ocupa de las ideas políticas en perspectiva histórica: ¿qué diferencia media entre ella y la historia de las ideas? ¿cuál es la utilidad que, para el filósofo, reviste examinar las ideas en su contexto?

La separación disciplinar, por decirlo así, entre la filosofía y la historia de las ideas no parece tan difícil. Mientras el filósofo aspiraría a la verdad de las afirmaciones filosóficas, el historiador perseguiría la verdad de las afirmaciones acerca de cómo, y en qué contexto, las ideas se desarrollaron (Kuntz 1969, p. 659). Esa sencillez desaparece, sin embargo, cuando se trata de precisar la utilidad que, para la filosofía, reviste la historia de las ideas que con ella se relacionan.

Entonces aparecen al menos cuatro alternativas. 
La primera de ellas surge de una nota de Wittgenstein escrita en 1916.

¿Qué tiene que hacer la historia conmigo? ¡El mío -concluye- es el primero y el único mundo! (Wittgenstein 1961, p. 82c).

Ese desdén por el estudio de la historia para la filosofía podría haber derivado del atomismo lógico que entonces influía a Wittgenstein o de la convicción de que la filosofía no era un punto de vista entre otros, sino uno sub aespecie aeternitatis. Si la única experiencia que tenemos es la actual o si el contenido normativo de la filosofía política (por ejemplo, la búsqueda de un modelo de buena vida, Wittgenstein 1916, p. 83c) debe ser sub aespecie aeternitatis, entonces el desdén por la historia de las ideas que surge de esa nota fluye como cosa natural.

Un punto de vista opuesto es el del historicismo. Para el historicismo, la utilidad del análisis histórico es hasta cierto punto paradójica, puesto que al emprenderlo la filosofía política enfrentaría la prueba de su propia imposibilidad. En efecto, ese quehacer mostraría que las respuestas que busca la filosofía política siempre se estrellan contra los muros invisibles del tiempo en que se formulan. La filosofía, podría decirse entonces, a pesar de su aparente vocación por la universalidad, solo sería capaz de dar respuestas, como suele decirse, "históricamente condicionadas" (Cfr. Strauss 1949, p. 33). Desde este punto de vista, el examen del pensamiento conservador en Chile en la perspectiva de la filosofía, solo podría confirmar una verdad incómoda: las ideas, incluso aquellas que se formulan con las armas sofisticadas de la reflexión filosófica, serían siempre hijas de su tiempo.

Aun podría ocurrir que al filósofo le interesen las ideas en perspectiva histórica porque esté convencido de que la multitud de respuestas que se han dado a las cuestiones de la filosofía política -v.gr. el sentido y los límites del poder, el valor de la temporalidad, etcétera- en vez de estrellar a la filosofía con los muros del tiempo, abra posibilidades para elaborar respuestas hoy día olvidadas (como se sugiere en Strauss 1949) o porque la historia, al asomarse al mundo de la vida, constituya una puerta de acceso a las verdades trascendentales (como comentando la preocupación de Husserl por la historia anota Gadamer, Cfr. Morrison 1977, p. 313).

Pero hay todavía una tercera alternativa, más alentadora para la filosofía y para el esfuerzo que en este libro se despliega. Aun podría ocurrir que al filósofo le interesen las ideas en perspectiva histórica no para acreditar que su vocación de universalidad está destinada al fracaso, sino para mostrar que las doctrinas políticas, y la reflexión filosófica que les subyace, ayudan a definir una época. Si, como enseña el historicismo, la filosofía estaría siempre históricamente condicionada, podría ocurrir que el examen de la historia de las ideas muestre que el acontecer histórico puede estar, por su parte, y por decirlo en términos algo laxos, "filosóficamente condicionado".

Esto último -y de una forma que en lo que sigue se examinará- es el supuesto del trabajo de Cristi y de Ruiz.

Ambos, en efecto, examinaron el pensamiento conservador en Chile -la obra de Edwards, Eyzaguirre, Encina, Góngora y Guzmán- como una forma de comprender el presente, como una forma de inteligir el Chile contemporáneo, porque ambos 
están convencidos de que las ideas que subyacen a la modernización capitalista de casi dos décadas, los conceptos que le confieren sentido a esa experiencia y que han permitido legitimarla, no habrían sido posibles sin el genio político de Guzmán o las ideas que empujaron gente como Eyzaguirre o como Góngora. La matriz ideológica de la modernización y de las instituciones que la soportan provendría en buena parte del pensamiento conservador. Este último, pues, habría tenido un efecto performativo, un poder constituyente de la cultura pública del Chile contemporáneo (Cristi y Ruiz 2015, p. 17).

Un intento como ese posee, sin embargo, una serie de supuestos conceptuales que, al igual que el pensamiento que procura inteligir, pueden ser a su vez interrogados. En el caso del trabajo de Ruiz y Cristi hay al menos cinco de esas cuestiones que merecen un análisis. Ellas están referidas al uso de la expresión pensamiento en vez de doctrina; a la precisión del momento en que esa forma de pensar brota, que los autores sitúan en 1903; al hecho de que de todos los autores examinados en este libro cuatro de ellos sean historiadores y a la distinción que el libro sugiere al interior del pensamiento conservador entre la tesis realista y la nobiliaria; y, en fin, a la influencia que esas ideas pudieron haber tenido en el Chile contemporáneo.

¿Por qué pensamiento en vez de doctrina conservadora?

La expresión "pensamiento conservador" como campo de estudio de la sociología del conocimiento la popularizó en un trabajo, de esa misma denominación, publicado en 1927, Karl Mannheim (Mannheim 2013, p. 74). Mannheim se proponía allí indagar en las variables sociales que hacían posible lo que llamó un "estilo de pensamiento", una cierta forma de experimentar el tiempo que se habría desatado junto con algunos fenómenos propios de la modernidad. Siempre habría existido tradicionalismo, la legitimidad del eterno ayer, dijo Mannheim; pero solo habría conservadurismo como forma de pensar a contar del XVIII en Europa. Así entendido el pensamiento conservador no es lo mismo que una doctrina conservadora. Mientras esta última se define por un conjunto sistemático de ideas y principios organizativos, el primero es un estilo de pensar frente a la experiencia del cambio moderno. Y por eso puede haber, como de hecho ha habido en Chile, un ejemplo es Alberto Edwards, liberales de mentalidad conservadora. Cuando los autores prefieren la expresión "pensamiento conservador" subrayan el hecho de que su objetivo no es sistematizar o narrar el contenido normativo del conservadurismo, sino su intención básica, o como prefiere Mannheim y con él la literatura que le siguió hasta hoy, su estilo.

¿Por qué los inicios del pensamiento conservador, debemos preguntar ahora en segundo lugar, podrían situarse, como los autores insinúan, el año 1903 ?

La razón que dan los autores de este libro es que el año 1903 se publica Bosquejo histórico de los partidos políticos de Alberto Edwards, donde se emprende una crítica frontal contra el parlamentarismo, que se agudizará, y se hará más densa luego, en $L a$ Fronda Aristocrática (Cristi y Ruiz 2015, pp. 13, 22).

Sin embargo, no es la publicación del libro sino más bien las circunstancias sociales que desatan su escritura lo que marca el inicio del pensamiento conservador. 
La literatura sitúa la aparición del pensamiento conservador en los umbrales de la modernidad. Por eso, los autores sitúan la aparición de este estilo de pensamiento en Rusia durante Alejandro I (Martin 1997, p. 5), en Francia durante Luis XV (Mathiez 1930, p. 99) o en Alemania luego de la Ilustración. La razón deriva del hecho de que es en los umbrales de la modernidad cuando la vida social es llamada a capítulo y cuando lo que hasta entonces se tenía por obvio es sometido a una permanente reflexividad; la vida social, como sugiere en una de sus páginas Tönnies, uno de los fundadores de la sociología clásica, se ve puesta en la necesidad, por decirlo así, de justificarse ante sí misma (Tönnies 1944, p. 27). Ese fenómeno es el que ocurre en el Chile de principios del XX cuando se verifica la cuestión social, se constata la crisis del orden oligárquico y un nuevo actor social, el proletariado urbano, comienza a aparecer en escena. El tradicionalismo que es un estilo muy antiguo, se transforma en conservadurismo, observó Mannheim, cuando el cambio y la dinámica social ocurren al interior del conflicto de clases. Cuando eso ocurre, la vida social busca donde anclarse y el poder se da entonces a la búsqueda de una "rectitud de origen", según la feliz expresión de Foucault: de un momento que le permita reclamar obediencia. No es entonces la publicación del Bosquejo histórico de los partidos políticos el año 1903 lo que marca el inicio del pensamiento conservador, sino los hechos sociales a los que, por decirlo así, se intenta llamar al orden, los que marcan ese comienzo: la reacción contra la influencia ilustrada en la esfera de las instituciones, primero; contra la crisis del orden oligárquico después, en el umbral del $\mathrm{XX}^{1}$. No es la publicación del libro entonces, sino la circunstancia ante la que Edwards reacciona, escribiéndolo, la que indica el comienzo del pensamiento conservador en Chile.

¿A qué se debe, cabría preguntarse ahora, que todos los autores examinados en este libro sean historiadores? ¿Hay acaso algún vínculo íntimo entre el conservadurismo y la historiografía?

Uno de los primeros que llamó la atención acerca del vínculo que media entre el conservadurismo y el tiempo, que explicaría la delectación del primero por la historia, fue, de nuevo, Karl Mannheim en su tesis de habilitación. Allí, Mannheim, inspirado sin duda por los estudios culturales de Alfred Weber, sugiere que hay una

1 En el diecinueve hubo, por supuesto, una presencia del conservadurismo; aunque no hay total acuerdo en torno a sus figuras. El caso más interesante de analizar es, desde luego, el de A. Bello (Cfr. Cristi y Ruiz 2015, pp. 173 y ss). Por mi parte, creo que es posible afirmar que Bello fue un hombre de mentalidad conservadora. Juan Egaña sería el representante típico del iluminismo utópico y católico que, con la consolidación del Estado nacional, habría sido olvidado por el ideologismo en favor de la funcionalidad de las estructuras. La figura de Andrés Bello, y antes de él, Manuel de Salas, según esta interpretación, serían, por su parte, el paradigma de la inteligencia acomodada a las instituciones. El fino eclecticismo del Código Civil y ese si es no es con el que uno se encuentra tantas veces a la hora de precisar algunos de sus principios, no serían más que una muestra de la mentalidad ideológica que lo inspira, una de esas mentalidades que sabe trascender la realidad, como lo hizo Bello muchas veces, pero no para dejarse seducir por esas ensoñaciones, sino para, a partir de ellas, construir poco a poco el orden. Conservadurismo pues, en estado casi puro. 
diferencia fundamental en la manera en que el progresismo y el conservadurismo, a los que denomina "estilos de pensamiento", experimentan el tiempo (Mannheim 2013, p. 109). Mientras el progresismo experimenta el presente como el comienzo del futuro, el conservadurismo considera al presente como el último punto que alcanzó el pasado. El presente es en un caso un punto de partida y en el otro un punto de llegada; un umbral del que se parte, en un caso, una posada a la que se llega en el otro. El conservador vería al presente como siendo uno con el pasado y de ahí entonces que su concepto de historia, continúa Mannheim, sea más espacial que temporal, y de ahí también por qué su reflexión histórica acentúe más la coexistencia en un grupo, la totalidad social, que la sucesión de acontecimientos que es, en cambio, lo que acentuaría el progresismo como estilo de pensamiento.

Hay todavía otra razón para el vínculo, que este libro pone de manifiesto, entre el pensamiento conservador y la historia. Lo que parece ocurrir es que en algún momento, justo en los umbrales de la modernidad (el surgimiento de los Estados nacionales, el mercado autorregulado, la cuestión social), el discurso histórico se emplea como un arma de lucha política, como un discurso que pretende configurar la realidad en vez de solo describirla, como una especie de profecía al revés: un discurso que modela el presente desde el pretérito. En algún sentido entonces el discurso conservador se constituye en torno al debate histórico concebido como un campo de batalla (Foucault 2014, pp. 157 y ss). Esto parece derivar del hecho de que el pensamiento conservador, al revés de lo que ocurre con el progresismo, examina la norma a la luz de los hechos, en cambio el progresismo estiraría los hechos para adecuarlos a la norma.

No es raro entonces que a la hora de caracterizar el pensamiento conservador chileno, los profesores Cristi y Ruiz no solo lo sitúen a inicios del siglo XX, es decir, en medio de la crisis del orden oligárquico, sino que distingan en él dos corrientes de inspiración obviamente histórica: una nacionalista y otra corporativista, la primera análoga, dicen los autores, a la tesis nobiliaria de Boulainvilliers y la segunda análoga, por su parte, a la tesis realista de Dubos (Cristi y Ruiz 2015, pp. 14, 173). Como es sabido, Boulainvilliers y Dubos, cuyos textos subyacen en algunos de los análisis que hace Montesquieu en El espíritu de las leyes, son los principales representantes del debate francés acerca de la situación de la nobleza en la Francia del XVIII y, según anota Foucault (Foucault 2014), fue en medio de ese debate que se constituyó a la historia como un campo intelectual de particular relevancia política. Mientras Boulainvilliers (en su texto de 1732, Ensayo sobre la nobleza de Francia, seguida de una disertación sobre sus orígenes) sugiere que los derechos de la nobleza preceden a los de la corona, Dubos, dos años después, en 1734 (en su Historia crítica del establecimiento de la monarquía), afirma la preeminencia de la corona sobre la base de identificar una alianza entre ésta y el imperio romano (Cfr. Baum 1979, p. 131)². Es notable la analogía que

2 En el caso ruso, por su parte, la literatura parece distinguir tres corrientes. Un conservadurismo romántico; un conservantismo noble, y otro religioso. El conservadurismo chileno también podría ser caracterizado de esa forma, como una mezcla de esos tres tipos ideales, y extender esa caracterización hasta el presente como estilo de pensamiento. Vid. Martin 1997. 
media entre la tesis realista y las de Edwards o Encina que apoyan la legitimidad presidencial, haciéndola derivar de la vieja legitimidad monárquica y subordinando a ella a las clases dirigentes, o la que media entre las tesis de Eyzaguirre o Lira, que tanto van a influir en Guzmán, empeñadas en subrayar el papel de los grupos intermedios como contención y límite del poder estatal y las tesis nobiliarias.

Ahora bien, el pensamiento conservador es, claro está, un estilo de pensamiento que florece bajo ciertas condiciones sociales, casi un modo de estar en el mundo y de experimentar el tiempo histórico, como acabamos de ver, pero también él posee un cierto contenido práctico, una cierta vocación por modelar la vida que tenemos en común y articular los intereses sociales o, si se prefiere, y para usar una expresión jurídica, pero que no está en este caso descaminada, el pensamiento conservador posee también una cierta vocación constituyente de la vida social. La pregunta que cabría entonces formular en fin es si acaso ese poder constituyente del conservadurismo fue efectivo en el caso de Chile.

La respuesta de Cristi y Ruiz -y que atinge a la relación entre la filosofía política y la historia de las ideas- es que sí, que fue efectivo, y tan efectivo que llegó a modelar las instituciones y casi la atmósfera de nuestra cultura hasta mimetizarse con casi todas las opiniones de la esfera pública, hasta que recién, y hace apenas unos años, principió a trizarse.

Por supuesto, ese resultado que el conservadurismo habría tenido en Chile-cuyo rasgo más notorio fue una suerte de tesis nobiliaria consistente en sintetizar, en una sola formación política, el autoritarismo y el mercado- fue el fruto de la labor de un intelectual, Jaime Guzmán, cuyo pensamiento y formación también se examina en la nueva edición de este libro.

Cada cierto tiempo, enseña Hegel, la vida social requiere cierta síntesis que absorba el pasado y al mismo tiempo lo supere. A ese movimiento lo llamó Aufhebung. Ese movimiento, cuando se trata de una cultura reflexiva, no se produce espontáneamente sino que requiere del trabajo de los intelectuales capaces de sintetizar, de conservar y al mismo tiempo superar, relatos aparentemente opuestos, pero que responden a los mismos intereses. Ese fue, sugiere este libro, el papel histórico de Jaime Guzmán, quien no fue ni un doctrinario ni un conservador teórico, sino un intelectual ideológico, para usar la categoría de Mannheim (que tanto gustaba a Góngora, según se ve en su trabajo sobre Juan Egaña; Góngora 1980), un político capaz de compatibilizar pragmáticamente, por decirlo así, a Vásquez de Mella con Hayek, a Donoso Cortés con Friedmann, a puntos de vista y formas de organizar la vida social que, para mentes menos agudas y sofisticadas que las de Guzmán, parecían agua y aceite.

¿Dio curso Guzmán, al sintetizar el pensamiento conservador, a un nuevo poder constituyente en Chile? A la luz del análisis de Cristi y Ruiz, un análisis que muestra la capacidad que tiene la filosofía para inteligir su propia época, no cabe duda de la respuesta: Guzmán logró instituir mediante la astucia de la razón, que poseía en alto grado, uno de los poderes con mayor capacidad constituyente del Chile contemporáneo, un poder ideológico con cuyos efectos todavía estamos hoy, cotidianamente, lidiando. 


\section{Referencias bibliográficas}

Baum, J. A. (1979), Montesquieu and Social Theory. Oxford: Pergamon Press.

Cristi, R. y C. Ruiz (2015), El pensamiento conservador en Chile. Seis ensayos. Santiago: Editorial Universitaria.

Foucault, M. (2014), Defender la sociedad. México: F.C.E.

Góngora, Mario (1980), "Un rasgo utópico en el pensamiento de Juan Egaña", Estudios de Historia de las Ideas y de Historia Social. Valparaíso: Ediciones Universitarias.

Kuntz, Paul G. (October, 1969), The Dialectic of Historicism and Anti-historicism, The Monist, Vol. 53, No. 4, Philosophy of the History of Philosophy, pp. 656670.

Lee, Dwight E. and Robert N. Beck (Apr., 1954), The Meaning of "Historicism" The American Historical Review, Vol. 59, No. 3, pp. 568-577.

Strauss, L. (Jan., 1949), Political Philosophy and History, Journal of the History of Ideas, Vol. 10, No. 1, pp. 30-50

Mannheim, K. (2013), Conservative Thought, en Essays on Sociology and Social Psychology, Collected Works of Karl Mannheim. Routledge.

Martin, Alexander(1997), Romantics, Reformers, Reactionaries. Russian Conservative Thought and Politics in the Reign of Alexander I. Northern Illinois: University Press.

Mathiez, A. (1930), La place de Montesquieu dans 1'Histoire des Doctrines Politiques du XVIII Siécle, Annales Historiques de la Révolution française. 7Anné, 38.

Morrison, J. (Mar. 1977), Husserl's "Crisis": Reflections on the Relationship of Philosophy and History, Philosophy and Phenomenological Research, Vol. 37, No. 3, pp. 312-330

Tönnies, F. (1944), Comunidad y sociedad (Gemeinschaft und Gesellschaft, 1887). Buenos Aires: Losada.

Wittgenstein, L. (1961), Notebooks 1914-1916, Edited by G.H. Von Wrigth and G.E.M. Anscombe. New York: Harper Brothers. 